\title{
Effects of Age and Hearing Loss on the Processing of Auditory Temporal Fine Structure
}

\author{
Brian C. J. Moore
}

\begin{abstract}
Within the cochlea, broadband sounds like speech and music are filtered into a series of narrowband signals, each of which can be considered as a relatively slowly varying envelope (ENV) imposed on a rapidly oscillating carrier (the temporal fine structure, TFS). Information about ENV and TFS is conveyed in the timing and short-term rate of nerve spikes in the auditory nerve. There is evidence that both hearing loss and increasing age adversely affect the ability to use TFS information, but in many studies the effects of hearing loss and age have been confounded. This paper summarises evidence from studies that allow some separation of the effects of hearing loss and age. The results suggest that the monaural processing of TFS information, which is important for the perception of pitch and for segregating speech from background sounds, is adversely affected by both hearing loss and increasing age, the former being more important. The monaural processing of ENV information is hardly affected by hearing loss or by increasing age. The binaural processing of TFS information, which is important for sound localisation and the binaural masking level difference, is also adversely affected by both hearing loss and increasing age, but here the latter seems more important. The deterioration of binaural TFS processing with increasing age appears to start relatively early in life. The binaural processing of ENV information also deteriorates somewhat with increasing age. The reduced binaural processing abilities found for older/hearing-impaired listeners may partially account for the difficulties that such listeners experience in situations where the target speech and interfering sounds come from different directions in space, as is common in everyday life.
\end{abstract}

Keywords Frequency discrimination - Envelope - Binaural processing - Interaural phase discrimination $\cdot$ Envelope processing $\cdot$ Intelligibility $\cdot$ Processing efficiency - Sound localization · Pitch

\footnotetext{
B. C. J. Moore $(\bowtie)$

Department of Experimental Psychology, University of Cambridge, Downing Street, CB2 3EB

Cambridge, UK

e-mail: bcjm@cam.ac.uk 


\section{Introduction}

Within the healthy cochlea, broadband sounds are decomposed into narrowband signals, each of which can be considered as a relatively slowly varying envelope (ENV) imposed on a rapidly oscillating carrier (the temporal fine structure, TFS). Information about ENV and TFS is conveyed in the timing and short-term rate of nerve spikes in the auditory nerve (Joris and Yin 1992). Following Moore (2014), a distinction is made between the physical ENV and TFS of the input signal $\left(E V_{p}\right.$ and TFS $\left.{ }_{\mathrm{p}}\right)$, the ENV and TFS at a given place on the basilar membrane $\left(\mathrm{ENV}_{\mathrm{BM}}\right.$ and $\mathrm{TFS}_{\mathrm{BM}}$ ), and the neural representation of $\mathrm{ENV}_{\mathrm{BM}}$ and $\mathrm{TFS}_{\mathrm{BM}}\left(\mathrm{ENV}_{\mathrm{n}}\right.$ and $\left.\mathrm{TFS}_{\mathrm{n}}\right)$. This paper reviews studies that separate the effects of hearing loss and age on the auditory processing of ENV and TFS.

\section{Effects of Age}

\subsection{Monaural Processing of TFS}

It is widely believed that the difference limen for frequency (DLF) of pure tones depends on the use of TFS information for frequencies up to 4-5 kHz (Moore 1973), and perhaps even up to $8 \mathrm{kHz}$ (Moore and Ernst 2012). If so, the DLF at low and medium frequencies provides a measure of TFS processing. Abel et al. (1990) and He et al. (1998) compared DLFs for young and older subjects with normal hearing (audiometric thresholds $\leq 20 \mathrm{~dB}$ HL from 0.25 to $4 \mathrm{kHz}$ ). In both studies, DLFs were larger by a factor of 2-4 for the older than for the younger subjects, suggesting that there is an effect of age. However, performance on other tasks (duration discrimination for Abel et al. and intensity discrimination for He et al.) was also poorer for the older group, suggesting that there may be a general effect of age that leads to reduced "processing efficiency". The effect of age cannot be attributed to reduced frequency selectivity, since auditory filters do not broaden with increasing age when absolute thresholds remain normal (Lutman et al. 1991; Peters and Moore 1992).

Monaural TFS processing has also been assessed using the TFS1 test (Hopkins and Moore 2007; Moore and Sek 2009). This requires discrimination of a harmonic complex tone $(\mathrm{H})$ from an inharmonic tone (I), created by shifting all components in the $\mathrm{H}$ tone up by a fixed amount in hertz, $\Delta \mathrm{f}$. The value of $\Delta \mathrm{f}$ is adaptively varied to determine the threshold. Both tones are passed through a fixed bandpass filter centred on the higher (unresolved) components, and a background noise is used to mask combination tones and components falling on the skirts of the filter. Evidence suggesting that performance on this test reflects sensitivity to TFS rather than the use of excitation-pattern cues is: (1) Performance on the TFS test does not worsen with increasing level, except when the level is very high (Moore and Sek 2009, 2011; Marmel et al. 2015); (2) Randomizing the level of the individual components would be expected to impair the ability to use excitation-pattern cues, but this has 
very little effect on performance of the TFS1 test (Jackson and Moore 2014); (3) Differences in excitation level between the $\mathrm{H}$ and I tones at the threshold value of $\Delta \mathrm{f}$, estimated using the $\mathrm{H}$ and $\mathrm{I}$ tones as forward maskers, are too small to be usable (Marmel et al. 2015).

Moore et al. (2012) used the TFS1 test with centre frequencies of 850 and $2000 \mathrm{~Hz}$ to test 35 subjects with audiometric thresholds $\leq 20 \mathrm{~dB}$ HL from 0.25 to $6 \mathrm{kHz}$ and ages from 22 to 61 years. There were significant correlations between age and the thresholds in the TFS1 test $(r=0.69$ and 0.57 for the centre frequencies of 850 and $2000 \mathrm{~Hz}$, respectively). However, TFS1 scores at $850 \mathrm{~Hz}$ were correlated with absolute thresholds at $850 \mathrm{~Hz}(\mathrm{r}=0.67)$, even though audiometric thresholds were within the normal range, making it hard to rule out an effect of hearing loss.

Füllgrabe et al. (2015) eliminated confounding effects of hearing loss by testing young (18-27 years) and older (60-79 years) subjects with matched audiograms. Both groups had audiometric thresholds $\leq 20 \mathrm{~dB}$ HL from 0.125 to $6 \mathrm{kHz}$. The TFS1 test was conducted using centre frequencies of 1 and $2 \mathrm{kHz}$. The older subjects performed significantly more poorly than the young subjects for both centre frequencies. Performance on the TFS1 task was not correlated with audiometric thresholds at the test frequencies. These results confirm that increased age is associated with a poorer ability to use monaural TFS cues, in the absence of any abnormality in the audiogram. It is hard to know whether this reflects a specific deficit in TFS processing or a more general reduction in processing efficiency.

\subsection{Monaural Processing of ENV}

Füllgrabe et al. (2015) also assessed sensitivity to ENV cues by measuring thresholds for detecting sinusoidal amplitude modulation imposed on a 4-kHz sinusoidal carrier. Modulation rates of 5, 30, 90, and $180 \mathrm{~Hz}$ were used to characterize the temporal-modulation-transfer function (TMTF). On average, thresholds (expressed as $20 \log _{10} m$, where $m$ is the modulation index) were 2-2.5 dB higher (worse) for the older than for the younger subjects. However, the shapes of the TMTFs were similar for the two groups. This suggests that increasing age is associated with reduced efficiency in processing ENV information, but not with reduced temporal resolution for ENV cues. Schoof and Rosen (2014) found no significant difference in either processing efficiency or the shape of TMTFs measured with noise-band carriers between young (19-29 years) and older (60-72 years) subjects with near-normal audiograms. It is possible that, with noiseband carriers, amplitude-modulation detection is limited by the inherent fluctuations in the carrier (Dau et al. 1997), making it hard to measure the effects of age. 


\subsection{Binaural Processing of TFS}

The binaural processing of TFS can be assessed by measuring the smallest detectable interaural phase difference (IPD) of a sinusoidal carrier relative to an IPD of $0^{\circ}$, keeping the envelope synchronous at the two ears. A task of this type is the TFSLF test (where LF stands for low-frequency) (Hopkins and Moore 2010b; Sek and Moore 2012). Moore et al. (2012) tested 35 subjects with audiometric thresholds $\leq 20 \mathrm{~dB}$ HL from 0.25 to $6 \mathrm{kHz}$ and ages from 22 to 61 years. The TFS-LF test was used at center frequencies of 500 and $850 \mathrm{~Hz}$. There were significant correlations between age and IPD thresholds at both $500 \mathrm{~Hz}(\mathrm{r}=0.37)$ and $850 \mathrm{~Hz}(\mathrm{r}=0.65)$. Scores on the TFS-LF task were not significantly correlated with absolute thresholds at the test frequency. These results confirm those of Ross et al. (2007) and Grose and Mamo (2010), and indicate that the decline in sensitivity to binaural TFS with increasing age is already apparent by middle age.

Füllgrabe et al. (2015) used the TFS-LF task with their young and older groups with matched (normal) audiograms, as described above. The older group performed significantly more poorly than the young group at both centre frequencies used (500 and $750 \mathrm{~Hz}$ ). The scores on the TFS-LF test were not significantly correlated with audiometric thresholds at the test frequencies. Overall, the results indicate that the ability to detect changes in IPD worsens with increasing age even when audiometric thresholds remain within the normal range.

The binaural masking level difference (BMLD) provides another measure of binaural sensitivity to TFS. The BMLD is the difference in the detection threshold between a condition where the masker and signal have the same interaural phase and level relationship, and a condition where the relationship is different. Although BMLDs can occur as a result of differences in $\mathrm{ENV}_{\mathrm{n}}$ for the two ears, it is generally believed that the largest BMLDs result from the use of TFS ${ }_{n}$. Because the BMLD represents a difference between two thresholds, it has the advantage that differences in processing efficiency across age groups at least partly cancel. Several researchers have compared BMLDs for young and older subjects with (near-) normal hearing (Pichora-Fuller and Schneider 1991, 1992; Grose et al. 1994; Strouse et al. 1998). All showed that BMLDs (usually for a $500-\mathrm{Hz}$ signal frequency) were smaller for older than for young subjects, typically by $2-4 \mathrm{~dB}$.

In summary, binaural TFS processing deteriorates with increasing age, even when audiometric thresholds are within the normal range.

\subsection{Binaural Processing of ENV}

King et al. (2014) measured the ability to discriminate IPD using amplitude-modulated sinusoids. The IPDs were imposed either on the carrier, TFS $\mathrm{p}_{\mathrm{p}}$, or the modulator, $\mathrm{ENV}_{\mathrm{p}}$. The carrier frequency, $f_{\mathrm{c}}$, was 250 or $500 \mathrm{~Hz}$ and the modulation frequency was $20 \mathrm{~Hz}$. They tested 46 subjects with a wide range of ages (18-83 years) and degrees of hearing loss. The absolute thresholds at the carrier frequencies of 250 and $500 \mathrm{~Hz}$ were not significantly correlated with age. Thresholds for detect- 
ing IPDs in $\mathrm{ENV}_{\mathrm{p}}$ were positively correlated with age for both carrier frequencies $\left(\mathrm{r}=0.62\right.$ for $f_{\mathrm{c}}=250 \mathrm{~Hz} ; \mathrm{r}=0.58$, for $\left.f_{\mathrm{c}}=500 \mathrm{~Hz}\right)$. The correlations remained positive and significant when the effect of absolute threshold was partialled out. These results suggest that increasing age adversely affects the ability to discriminate IPDs in $\mathrm{ENV}_{\mathrm{p}}$, independently of the effects of hearing loss.

\section{Effects of Cochlear Hearing Loss}

\subsection{Monaural Processing of TFS}

Many studies have shown that cochlear hearing loss is associated with larger than normal DLFs. For a review, see Moore (2014). However, in most studies the hearing-impaired subjects were older than the normal-hearing subjects, so some (but probably not all) of the effects of hearing loss may have been due to age. DLFs for hearing-impaired subjects are not correlated with measures of frequency selectivity (Tyler et al. 1983; Moore and Peters 1992), confirming that DLFs depend on TFS information and not excitation-pattern information.

Several studies have shown that cochlear hearing loss is associated with a greatly reduced ability to perform the TFS1 test or similar tests (Hopkins and Moore 2007, 2010a, 2011). Many hearing-impaired subjects cannot perform the task at all. Although the effects of hearing loss and age were confounded in some of these studies, the performance of older hearing-impaired subjects seems to be much worse than that of older normal-hearing subjects, suggesting that hearing loss per se adversely affects monaural TFS processing.

\subsection{Monaural Processing of ENV}

Provided that the carrier is fully audible, the ability to detect amplitude modulation is generally not adversely affected by cochlear hearing loss and may sometimes be better than normal, depending on whether the comparison is made at equal sound pressure level or equal sensation level (Bacon and Viemeister 1985; Bacon and Gleitman 1992; Moore et al. 1992; Moore and Glasberg 2001). When the modulation is clearly audible, a sound with a fixed modulation depth appears to fluctuate more for an impaired ear than for a normal ear, probably because of the effects of loudness recruitment (Moore et al. 1996).

\subsection{Binaural Processing of TFS}

Many studies of the effects of hearing loss on discrimination of interaural time differences (ITDs) are confounded by differences in age between the normal-hearing 
and hearing-impaired subjects. One exception is the study of Hawkins and Wightman (1980). They measured just noticeable differences in ITD using low-frequency (450 $550 \mathrm{~Hz})$ and high-frequency $(3750-4250 \mathrm{~Hz})$ narrow-band noise stimuli. The ITD was present in both TFS $_{p}$ and $\mathrm{ENV}_{\mathrm{p}}$, except that the onsets and offsets of the stimuli were synchronous across the two ears. Performance was probably dominated by the use of TFS cues for the low frequency and ENV cues for the high frequency. They tested three normal-hearing subjects (mean age 25 years) and eight subjects with hearing loss (mean age 27 years). The two groups were tested both at the same sound pressure level (85 dB SPL) and at the same sensation level (30 dB SL). ITD thresholds were significantly higher for the hearing-impaired than for the normal-hearing subjects for both signals at both levels. These results suggest that cochlear hearing loss can adversely affect the discrimination of ITD carried both in TFS $\mathrm{p}_{\mathrm{p}}$ and in $\mathrm{ENV}_{\mathrm{p}}$.

The study of King et al. (2014), described above, is relevant here. Recall that they tested 46 subjects with a wide range of ages (18-83 years) and degrees of hearing loss. Thresholds for detecting IPDs in TFS were positively correlated with absolute thresholds for both carrier frequencies $\left(\mathrm{r}=0.45\right.$ for $f_{\mathrm{c}}=250 \mathrm{~Hz} ; \mathrm{r}=0.40$, for $f_{\mathrm{c}}=500 \mathrm{~Hz}$ ). The correlations remained positive and significant when the effect of age was partialled out. Thus, hearing loss adversely affects the binaural processing of TFS.

Many studies have shown that BMLDs are reduced for people with cochlear hearing loss, but again the results are generally confounded with the effects of age. More research is needed to establish the extent to which BMLDs are affected by hearing loss per se.

\subsection{Binaural Processing of ENV}

Although the results of Hawkins and Wightman (1980), described in Sect. 3.3, suggested that hearing loss adversely affected the discrimination of ITD carried in ENV King et al. (2014) found that thresholds for detecting IPDs in $\mathrm{ENV}_{\mathrm{p}}$ were not significantly correlated with absolute thresholds. Also, Léger et al. (2015) reported that thresholds for detecting IPDs in $\mathrm{ENV}_{\mathrm{p}}$ were similar for subjects with normal and impaired hearing (both groups had a wide range of ages). Overall, the results suggest that hearing loss does not markedly affect the ability to process binaural ENV cues.

\section{Summary and Implications}

The monaural and binaural processing of TFS is adversely affected by both increasing age and cochlear hearing loss. The efficiency of processing monaural ENV information may be adversely affected by increasing age, but the temporal resolution of ENV cues appears to be unaffected. The processing of binaural ENV information is adversely affected by increasing age. Cochlear hearing loss does not markedly affect the processing of monaural or binaural ENV information.

The effects of age and hearing loss on TFS processing may partially explain the difficulties experienced by older hearing-impaired people in understanding 
speech in background sounds (Hopkins and Moore 2010a, 2011; Neher et al. 2012; Füllgrabe et al. 2015).

Acknowledgments This work was supported by grant G0701870 from the MRC (UK). I thank Tom Baer, Hedwig Gockel, and Pim van Dijk for helpful comments.

Open Access This chapter is distributed under the terms of the Creative Commons AttributionNoncommercial 2.5 License (http://creativecommons.org/licenses/by-nc/2.5/) which permits any noncommercial use, distribution, and reproduction in any medium, provided the original author(s) and source are credited.

The images or other third party material in this chapter are included in the work's Creative Commons license, unless indicated otherwise in the credit line; if such material is not included in the work's Creative Commons license and the respective action is not permitted by statutory regulation, users will need to obtain permission from the license holder to duplicate, adapt or reproduce the material.

\section{References}

Abel SM, Krever EM, Alberti PW (1990) Auditory detection, discrimination and speech processing in ageing, noise sensitive and hearing-impaired listeners. Scand Audiol 19:43-54

Bacon SP, Gleitman RM (1992) Modulation detection in subjects with relatively flat hearing losses. J Speech Hear Res 35:642-653

Bacon SP, Viemeister NF (1985) Temporal modulation transfer functions in normal-hearing and hearing-impaired subjects. Audiology 24:117-134

Dau T, Kollmeier B, Kohlrausch A (1997) Modeling auditory processing of amplitude modulation. I. Detection and masking with narrowband carriers. J Acoust Soc Am 102:2892-2905

Füllgrabe C, Moore BCJ, Stone MA (2015) Age-group differences in speech identification despite matched audiometrically normal hearing: contributions from auditory temporal processing and cognition. Front Aging Neurosci 6(347): 1-25

Grose JH, Mamo SK (2010) Processing of temporal fine structure as a function of age. Ear Hear 31:755-760

Grose JH, Poth EA, Peters RW (1994) Masking level differences for tones and speech in elderly listeners with relatively normal audiograms. J Speech Hear Res 37:422-428

Hawkins DB, Wightman FL (1980) Interaural time discrimination ability of listeners with sensorineural hearing loss. Audiology 19:495-507

He N, Dubno JR, Mills JH (1998) Frequency and intensity discrimination measured in a maximum-likelihood procedure from young and aged normal-hearing subjects. J Acoust Soc Am 103:553-565

Hopkins K, Moore BCJ (2007) Moderate cochlear hearing loss leads to a reduced ability to use temporal fine structure information. J Acoust Soc Am 122:1055-1068

Hopkins K, Moore BCJ (2010a) The importance of temporal fine structure information in speech at different spectral regions for normal-hearing and hearing-impaired subjects. J Acoust Soc Am 127:1595-1608

Hopkins K, Moore BCJ (2010b) Development of a fast method for measuring sensitivity to temporal fine structure information at low frequencies. Int J Audiol 49:940-946

Hopkins K, Moore BCJ (2011) The effects of age and cochlear hearing loss on temporal fine structure sensitivity, frequency selectivity, and speech reception in noise. J Acoust Soc Am 130:334-349

Jackson HM, Moore BCJ (2014) The role of excitation-pattern and temporal-fine-structure cues in the discrimination of harmonic and frequency-shifted complex tones. J Acoust Soc Am 135:1356-1570

Joris PX, Yin TC (1992) Responses to amplitude-modulated tones in the auditory nerve of the cat. J Acoust Soc Am 91:215-232 
King A, Hopkins K, Plack CJ (2014) The effects of age and hearing loss on interaural phase discrimination. J Acoust Soc Am 135:342-351

Léger A, Heinz MG, Braida LD, Moore BCJ (2015) Sensitivity to interaural time differences in envelope and fine structure, individually and in combination. In: ARO 38th Annual Midwinter Meeting (Abstract PS-703). ARO, Baltimore, MD

Lutman ME, Gatehouse S, Worthington AG (1991) Frequency resolution as a function of hearing threshold level and age. J Acoust Soc Am 89:320-328

Marmel F, Plack CJ, Hopkins K, Carlyon RP, Gockel HE, Moore BCJ (2015) The role of excitationpattern cues in the detection of frequency shifts in bandpass-filtered complex tones. J Acoust Soc Am 137:2687-2697

Moore BCJ (1973) Frequency difference limens for short-duration tones. J Acoust Soc Am 54:610-619

Moore BCJ (2014) Auditory processing of temporal fine structure: effects of age and hearing loss. World Scientific, Singapore

Moore BCJ, Ernst SM (2012) Frequency difference limens at high frequencies: evidence for a transition from a temporal to a place code. J Acoust Soc Am 132:1542-1547

Moore BCJ, Glasberg BR (2001) Temporal modulation transfer functions obtained using sinusoidal carriers with normally hearing and hearing-impaired listeners. J Acoust Soc Am 110:1067-1073

Moore BCJ, Peters RW (1992) Pitch discrimination and phase sensitivity in young and elderly subjects and its relationship to frequency selectivity. J Acoust Soc Am 91:2881-2893

Moore BCJ, Sek A (2009) Development of a fast method for determining sensitivity to temporal fine structure. Int J Audiol 48:161-171

Moore BCJ, Sek A (2011) Effect of level on the discrimination of harmonic and frequency-shifted complex tones at high frequencies. J Acoust Soc Am 129:3206-3212

Moore BCJ, Shailer MJ, Schooneveldt GP (1992) Temporal modulation transfer functions for band-limited noise in subjects with cochlear hearing loss. Br J Audiol 26:229-237

Moore BCJ, Wojtczak M, Vickers DA (1996) Effect of loudness recruitment on the perception of amplitude modulation. J Acoust Soc Am 100:481-489

Moore BCJ, Vickers DA, Mehta A (2012) The effects of age on temporal fine structure sensitivity in monaural and binaural conditions. Int J Audiol 51:715-721

Neher T, Lunner T, Hopkins K, Moore BCJ (2012) Binaural temporal fine structure sensitivity, cognitive function, and spatial speech recognition of hearing-impaired listeners. J Acoust Soc Am 131:2561-2564

Peters RW, Moore BCJ (1992) Auditory filters and aging: filters when auditory thresholds are normal. In: Cazals Y, Demany L, Horner K (eds) Auditory physiology and perception. Pergamon, Oxford, pp 179-185

Pichora-Fuller MK, Schneider BA (1991) Masking-level differences in the elderly: a comparison of antiphasic and time-delay dichotic conditions. J Speech Hear Res 34:1410-1422

Pichora-Fuller MK, Schneider BA (1992) The effect of interaural delay of the masker on maskinglevel differences in young and old subjects. J Acoust Soc Am 91:2129-2135

Ross B, Fujioka T, Tremblay KL, Picton TW (2007) Aging in binaural hearing begins in mid-life: evidence from cortical auditory-evoked responses to changes in interaural phase. J Neurosci 27:11172-11178

Schoof T, Rosen S (2014) The role of auditory and cognitive factors in understanding speech in noise by normal-hearing older listeners. Front Aging Neurosci 6(307):1-14

Sek A, Moore BCJ (2012) Implementation of two tests for measuring sensitivity to temporal fine structure. Int J Audiol 51:58-63

Strouse A, Ashmead DH, Ohde RN, Grantham DW (1998) Temporal processing in the aging auditory system. J Acoust Soc Am 104:2385-2399

Tyler RS, Wood EJ, Fernandes MA (1983) Frequency resolution and discrimination of constant and dynamic tones in normal and hearing-impaired listeners. J Acoust Soc Am 74:1190-1199 